\title{
Hospitalização na gravidez de alto risco: represen- taçóes sociais das gestantes
}

Hospital admission in high-risk pregnancies: the social representations of pregnant women

\author{
Hospitalización en el embarazo de alto riesgo: representaciones sociales de las mu- \\ jeres embarazadas
}

Antonia Regynara Moreira Rodrigues ${ }^{1}$

(D) https://orcid.org/0000-0001-7495-2328

Dafne Paiva Rodrigues ${ }^{1}$

(Dhttps://orcid.org/0000-0001-8686-3496

Maria Adelaide Moura da Silveira ${ }^{1}$

Dhttps://orcid.org/0000-0001-7290-9991

Antonia de Maria Gomes Paiva ${ }^{1}$

(D) https://orcid.org/0000-0002-5743-1819

Ana Virgínia de Melo Fialho ${ }^{1}$

(D) https://orcid.org/0000-0002-4471-1758

Ana Beatriz Azevedo Queiroz ${ }^{2}$

(D) https://orcid.org/0000-0003-2447-6137

${ }^{1}$ Universidade Estadual do Ceará, Fortaleza, Ceará, Brasil

${ }^{2}$ Universidade Federal do Rio de Janeiro, Rio de Janeiro, Rio de Janeiro, Brasil

Autor de correspondência Antonia Regynara Moreira Rodrigues E-mail: regynararodrigues@yahoo.com.br

Recebido: 02.04.20

Aceite: 16.06 .20

\section{Resumo}

Enquadramento: A hospitalização na gravidez de alto risco gera alteraçóes na rotina e na forma de compreender a gravidez, que devem ser consideradas durante o planeamento e execução da assistência. Objetivo: Conhecer as representaçóes sociais de gestantes de alto risco sobre a hospitalizaçáo durante o ciclo gravídico.

Metodologia: Estudo exploratório, descritivo, norteado pela teoria das representaçóes sociais, realizado em duas maternidades do Ceará com 68 gestantes de alto risco hospitalizadas, entre julho e setembro de 2016, através do teste de associação livre de palavras com análise pelo software Tri-Deux-Mots, versão 5.3. Resultados: A gravidez foi representada pela satisfação de gestar, ancorada na funçáo biológica e social da maternidade, a gravidez de alto risco foi apreendida como situaçáo problemática e de desfecho incerto, envolta em sentimentos negativos. A hospitalização foi interpretada como lugar de dor e solidão, mas também de cuidado e proteção, ampliando possibilidades de evolução favorável.

Conclusáo: As evocaçóes elucidam conteúdos significativos sobre gravidez com as particularidades do diagnóstico de alto risco e do contexto da hospitalizaçáo.

Palavras-chave: gestantes; gravidez; gravidez de alto risco; hospitalização; psicologia social

\section{Abstract}

Background: Hospital admission in high-risk pregnancies changes the routine and the way in which pregnancy is experienced. These changes must be taken into account during care planning and delivery. Objective: To identify high-risk pregnant women's social representations of hospital admission during pregnancy.

Methodology: An exploratory, descriptive study, guided by the social representations theory, was carried out in two maternity hospitals in Ceará, involving 68 hospitalized high-risk pregnant women, between July and September 2016. The word association test was used and data were analyzed using the Tri-Deux-Mots software, version 5.3.

Results: Pregnancy was represented by the satisfaction to gestate a baby, anchored in the biological and social role of motherhood. High-risk pregnancy was perceived as a problematic situation with an uncertain outcome, surrounded by negative feelings. Hospital admission was interpreted as a place of pain and loneliness, but also of care and protection, expanding the possibilities for a favorable evolution. Conclusion: The evoked words reflect important meanings attributed to pregnancy in a context of a high-risk pregnancy that requires hospital admission.

Keywords: pregnant women; pregnancy; pregnancy, high-risk; hospitalization; psychology, social

\section{Resumen}

Marco contextual: La hospitalización en los embarazos de alto riesgo provoca cambios en la rutina y en la forma de comprender el embarazo, que deben considerarse durante la planificación y la implementación de la atención.

Objetivo: Conocer las representaciones sociales de las mujeres embarazadas de alto riesgo sobre la hospitalización durante el ciclo de embarazo.

Metodología: Estudio exploratorio y descriptivo, guiado por la teoría de las representaciones sociales, realizado en dos maternidades de Ceará con 68 mujeres embarazadas de alto riesgo hospitalizadas entre julio y septiembre de 2016, mediante la prueba de asociación libre de palabras, analizada con el software Tri-Deux-Mots, versión 5.3.

Resultados: El embarazo se representó por la satisfacción del mismo, anclada en la función biológica y social de la maternidad; el embarazo de alto riesgo se percibió como una situación problemática y de resultado incierto, rodeada de sentimientos negativos. La hospitalización se interpretó como un lugar de dolor y soledad, pero también de cuidado y protección, que amplía las posibilidades de evolución favorable.

Conclusión: Las evocaciones aclaran contenidos significativos sobre el embarazo, con las particularidades del diagnóstico de alto riesgo y del contexto de la hospitalización.

Palabras clave: mujeres embarazadas; embarazo; embarazo de alto riesgo; hospitalización; psicología social
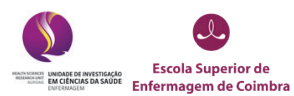

Como citar este artigo: Rodrigues, A. R. M., Rodrigues, D. P., Silveira, M. A., Paiva, A. M., Fialho, A. V., \& Queiroz, A. B. (2020). Hospitalização na gravidez de alto risco: representaçōes sociais das gestantes. Revista de Enfermagem Referência, 5(3), e20040. doi:10.12707/RV20040 


\section{Introdução}

A gestação é um evento complexo e singular, envolto em modificaçóes físicas, psicológicas e sociais, considerado natural e fisiológico, que transcorre sem intercorrências para a mulher e/ou o feto e para o qual as complicaçóes que podem comprometer a evolução da gravidez estão previstas em apenas 20\% dos casos. Nestes casos, denominados como gravidez de alto risco, uma série ampla de condiçôes clínicas ou clínico-obstétricas, que podem ser ocasionadas pela gravidez ou pré-existentes e agravadas pela gestação, ameaçam o bem-estar materno-fetal e expóem o binómio ao risco de desfechos desfavoráveis (Ministério da Saúde, 2012).

Apesar da gravidez de alto risco atingir uma parcela minoritária das mulheres, traz amplas implicações a níveis epidemiológicos, emocionais, económicos e sociais. Sabe-se que a gravidez de alto risco se associa a causas de morbimortalidade materna e perinatal, além de um aumento nos gastos para o setor da saúde, pela necessidade de atendimento especializado, custos com procedimentos e internamentos hospitalares (Lawn et al., 2016; Martins \& Silva, 2018; Moura, Alencar, Silva, \& Almeida, 2018). Além disso, a gestação de alto risco é associada a uma multiplicidade de sentimentos negativos como ansiedade, medo, culpa, insegurança, dificuldades de aceitação, o que provoca vulnerabilidade e instabilidade emocional (Cabral et al., 2018; Wilhelm et al., 2015; Oliveira \& Mandú, 2015).

No contexto da gravidez de alto risco, a hospitalização é um procedimento necessário para vigilância e acompanhamento da gestação, o que intensifica e particulariza a experiência das gestantes, uma vez que são afastadas do seu convívio doméstico e da sua rotina, inseridas num ambiente novo, passando a conviver com outras gestantes e profissionais de saúde, com avaliações diárias por uma equipa multiprofissional, fármacos, exames e procedimentos, que resultam em stress adicional e necessidades de adaptação (Costa et al., 2019; Piveta, Bernardy, \& Sodré, 2016).

Frente ao contexto apresentado, importa compreender a gravidez de alto risco no contexto da hospitalização a partir da dinâmica social das gestantes, da sua maneira de conhecer e interpretar as situaçóes da vida, dos seus comportamentos, das suas atitudes, das suas escolhas, valores, crenças, discursos, comunicação e sentidos que agregam valor ao fenómeno para elas próprias. Assim, o referencial teórico das representaçōes sociais foi adotado por possibilitar perceber os indivíduos no seu quotidiano, como ocorrem os seus processos de conhecer, assimilar e compreender os factos e como o conhecimento construído sobre estes factos é expresso nas suas interaçóes, na sua comunicação e nos seus comportamentos (Moscovici, 2013).

A teoria das representaçóes sociais reconhece o valor da dimensão subjetiva, o aspeto cognitivo do indivíduo, o que interfere nas atitudes, nas condutas, no conhecimento e no comportamento em relação ao objeto da representação (Moscovici, 2013). Diante disto, objetivou-se conhecer as representaçóes sociais de gestantes de alto risco sobre a hospitalização durante o ciclo gravídico.

\section{Enquadramento}

O processo gestacional é um fenómeno dinâmico e multidimensional para a mulher, para o seu companheiro e para os seus familiares, devido às características clínicas, sociais, culturais e representacionais deste. Representa, no universo familiar, um processo transformador, envolvido por expectativas, anseios e inseguranças perante o que será vivenciado e pela aquisição de novos papéis e responsabilidades (Cabral et al., 2018).

O ciclo gravídico-puerperal, embora consista num período de vivências saudáveis, pode ser acompanhado por condições clínicas, obstétricas e sociais capazes de expor o binómio materno-fetal a maior probabilidade de desfechos desfavoráveis. Esse grupo representa o chamado alto risco, que atualmente corresponde a $20 \%$ das gestações no Brasil, cujos diagnósticos mais prevalentes correspondem a infeçôes, perda de líquido amniótico, hemorragias, alteraçóes metabólicas e da pressão arterial (Ministério da Saúde, 2012).

Como consequências, encontra-se na literatura uma forte associação com parto prematuro, baixo peso ao nascer, restrição de crescimento intrauterino, mortalidade perinatal, internamentos em serviços de cuidados intensivos maternos, neonatais e mortalidade materna, tanto no Brasil como no mundo (Lawn et al., 2016; Martins \& Silva, 2018; Moura et al., 2018). Destarte, ao receberem o diagnóstico de gravidez de alto risco, passam por uma experiência singular e stressante devido aos riscos a que estão submetidos o feto e a mãe, manifestando sentimentos de culpa, medo, ansiedade, receio, podendo apresentar dificuldades para exercer papéis estabelecidos pela sociedade e, por consequência, sofrer alteraçóes na sua rotina e na sua qualidade de vida (Costa et al., 2019).

A gestação de alto risco requer vigilância das situações de gravidade e prontidão para identificar problemas e intervir de maneira a impedir eventuais complicaçóes. Neste contexto, a qualidade da assistência prestada e o acesso a serviços de saúde especializados que possa atender as necessidades das utentes são fundamentais para a prevenção da morbidade e da mortalidade materno-fetais (Sousa, Sales, Oliveira, \& Chagas, 2018).

Com o objetivo de assegurar a qualidade da assistência a estas gestantes, o Ministério da Saúde do Brasil desenvolveu políticas de atenção à mulher, como o Programa Nacional de Humanização do Pré-Natal e Nascimento, a Política Nacional de Assistência Integral à Saúde da Mulher e a Rede Cegonha, como pacote de açóes e medidas que visam estruturar uma rede de cuidados para garantir às mulheres uma atenção qualificada e humanizada à gravidez, ao parto e ao puerpério e às crianças o nascimento seguro e o crescimento e desenvolvimento saudáveis, além de redução dos elevados índices de morbimortalidade materno-infantil (Sehnem, Saldanha, Arboit, Ribeiro, \& Paula, 2020).

De acordo com as recomendações do Ministério da Saúde, o atendimento à gestante de risco deve contemplar uma abordagem integral em todos os níveis de atenção conforme as suas especificidades clínicas, socioeconómicas e demográficas e deve ser constituído por atenção 
multiprofissional e interdisciplinar, com práticas clínicas compartilhadas e baseadas em evidências, com o objetivo principal de reduzir os riscos de eventuais complicações para a mãe e/ou feto (Ministério da Saúde, 2012; Portaria $\mathrm{n}^{\circ} 1.020$, de 29 de maio de 2013).

Em virtude de algumas condições ou iminência maior de complicações, a hospitalizaçáo é o procedimento mais adequado para o acompanhamento dessa gestação (Ministério da Saúde, 2012). Os períodos de internamento na gestação de alto risco normalmente são longos, podendo variar de semanas até meses em enfermarias pequenas, tendo que compartilhar espaços reduzidos, numa convivência intensa com outras pacientes, recebendo avaliaçôes diárias dos profissionais de saúde, o que legitima o risco para as gestantes (Coelho, Souza, Torres, \& Drezett, 2017; Costa et al., 2019; Gregorio \& Mariot, 2019).

Atualmente encontram-se estudos que atribuem importância elevada à experiência vivida pelas mulheres internadas com gravidez de alto risco, quer seja pelas dificuldades reveladas sobre o entendimento da situação ou pela morosa adaptação às circunstâncias que conduziram ao internamento, quer pela expectativa frustrada da gravidez ou pelos diversos sentimentos experienciados (Wilhelm et al., 2015; Oliveira \& Mandú, 2015). Outros estudos evidenciaram que mulheres com gestaçôes de alto risco são vulneráveis à fragilidade e à instabilidade emocional, uma vez que apresentam sentimentos negativos, o que pode ocasionar sensação de mal-estar e dificuldades de aceitação do diagnóstico de alto risco, que podem exercer um efeito direto sobre a saúde (Coelho et al., 2017; Costa et al., 2019).

Desta forma, a complexidade que envolve a gestaçáo de alto risco não deve ser limitada apenas ao aspeto biológico, à determinação das suas causas e consequências e ao tratamento das intercorrências, nem à descrição dos sentimentos, mas compreendê-la na dinâmica social destas mulheres. Assim, este estudo considera a necessidade de conhecer a gravidez de alto risco em processo de hospitalização a partir dos conteúdos significativos para as gestantes de alto risco, de modo a permitir aos profissionais de saúde o desenho de uma assistência efetiva e que contemple a individualidade e a integralidade da atenção a estas mulheres.

\section{Questáo de investigação}

Quais as representações sociais de gestantes de alto risco sobre a hospitalização durante o ciclo gravídico?

\section{Metodologia}

Estudo exploratório e descritivo, norteado pela teoria das representaçóes sociais. Desenvolvido com 68 gestantes de alto risco hospitalizadas em duas maternidades públicas de referência no estado do Ceará entre os meses de julho a setembro de 2016. As maternidades foram selecionadas por serem serviços terciários especializados, referência para gravidez de alto risco e por realizarem o maior número de partos de alto risco no estado.

$\mathrm{O}$ número de participantes correspondeu à totalidade de gestantes que cumpriram os seguintes critérios de inclusão: estar hospitalizada há no mínimo 72 horas cuja razão seja a existência de risco para o desenvolvimento da gestaçáo, independentemente da idade gestacional. Este período de hospitalização foi estabelecido considerando que as representaçóes sociais são concebidas a partir do conhecimento e interação com o fenómeno, pelo que ampliar o contacto das gestantes com o serviço e, consequentemente, o leque de experiências vivenciadas, favorece a elaboração das representaçôes. A aceitabilidade das gestantes em participar no estudo implicou a assinatura do Termo de Consentimento Livre e Esclarecido para as maiores de 18 anos e assinatura do Termo de Assentimento para as com idade inferior a 18 anos e do Termo de Consentimento Livre e Esclarecido pelos seus pais.

Os dados foram colhidos através da aplicação do Teste de Associação Livre de Palavras (TALP), uma técnica projetiva que favorece os indivíduos a revelarem o conteúdo latente da memória em relação a um determinado objeto implícito, muitas vezes, nos seus depoimentos. O TALP é um instrumento adaptado ao campo da psicologia social que tem vindo a enriquecer as pesquisas em representações sociais, e consiste na evocação de ideias a partir de estímulos indutores, que devem ser definidos com base no objeto pesquisado (Coutinho, 2017).

Para realização do teste foram escolhidos os estímulos indutores: gravidez, gravidez de risco e internamento, por estarem intimamente ligados ao objeto deste estudo e próximos ao universo vocabular das gestantes. Após a aplicação do teste, elaborou-se um banco de dados composto pelo conjunto de palavras evocadas correspondente a cada estímulo indutor e por variáveis fixas para identificação e caracterização das gestantes, as quais foram: local de internamento (1- Santa Casa de Misericórdia de Sobral; 2 - Hospital Geral César Cals); número de gestações (1 - primigesta; 2 - multigesta) e tipo de risco (1 - decorrente da gestaçáo; 2 - pré-existente agravado). Os dados foram analisados com o auxílio do software Tri-Deux-Mots, versão 5.3, que possibilita uma interpretação a partir da análise fatorial de correspondência (AFC), representando graficamente num plano fatorial as correlaçóes entre variáveis fixas (em colunas) e as modalidades ou variáveis de opinióes (em linhas), visualizando as aproximaçôes, afastamentos, confrontos e atraçóes entre os grupos. A análise pelo software Tri-Deux-Mots permite representar em eixos fatoriais as palavras evocadas e definir as relaçôes de proximidade e distanciamento entre os universos semânticos do campo representacional, tendo como referência as variáveis fixas e as variáveis de opinião ou estímulos indutores. Possibilita ainda examinar as ligaçóes entre os perfis de respostas num dado grupo através das palavras que mais contribuíram para a formação dos eixos, consideradas as modalidades de opinióes ou objetivaçóes. Os aspetos éticos para o desenvolvimento de investigação com seres humanos foram respeitados. A presente investigação recebeu aprovação do Comitê de Ética em Pesquisa da Universidade Estadual do Ceará e do Hospital Geral Dr. César Cals, com números 1.532 .814 e 1.630 .695 e CAAE 53573216.0.0000.5534 e 56479316.7.0000.504, respectivamente, assim como autorização da comissão 
científica de pesquisa da Santa Casa de Misericórdia de Sobral.

\section{Resultados}

As participantes do estudo eram gestantes, cujas idades variaram entre 15 e 41 anos, sendo predominante a faixa etária entre 15-25 anos (47,1\%), que frequentaram até ao ensino médio (44,2\%), com companheiro fixo $(77,9 \%)$, que exerciam atividade remunerada $(51,5 \%)$ e professaram fé católica $(63,2 \%)$. Multigestas $(64,7 \%)$, no terceiro trimestre $(82,4 \%)$, sendo o risco decorrente da gravidez prevalente para 82,4\% das gestantes.

Quanto à duração da hospitalização, verificou-se variação entre 3 e 60 dias, com uma média de 6,9 dias, pelos diagnósticos mais frequentes: pré-eclâmpsia $(20,6 \%)$; rotura anteparto de membranas ovulares $(19,1 \%)$; diabetes $(11,8 \%)$; ameaça de parto prematuro $(10,3 \%)$; e placenta prévia $(10,3 \%)$.
Foram obtidas 606 palavras evocadas, sendo que destas, 68 eram diferentes, e possibilitaram a aproximação com os conteúdos consensuais compartilhados pelas gestantes no campo das representaçóes sociais sobre a gestação de alto risco no contexto da hospitalização. A análise pelo software Tri-Deux-Mots, por sua vez, permite representar em eixos fatoriais (F1 e F2) como se estruturam as representações sociais sobre um dado fenómeno no grupo em estudo, colocando em evidência os elementos semânticos que constituem o universo comum às gestantes face aos diferentes estímulos.

A Figura 1 representa os dois eixos, eixo F1 (eixo horizontal) e eixo F2 (eixo vertical). As variáveis fixas estão representadas pela cor verde, onde LOC refere-se ao local de internamento, GES ao número de gestaçóes e RIS ao tipo de risco. As palavras referentes ao Fator 1 encontram-se destacadas pela cor vermelha, enquanto as do Fator 2 pela cor azul, e os números 1 , 2 e 3 que acompanham as evocaçóes equivalem ao estímulo indutor.

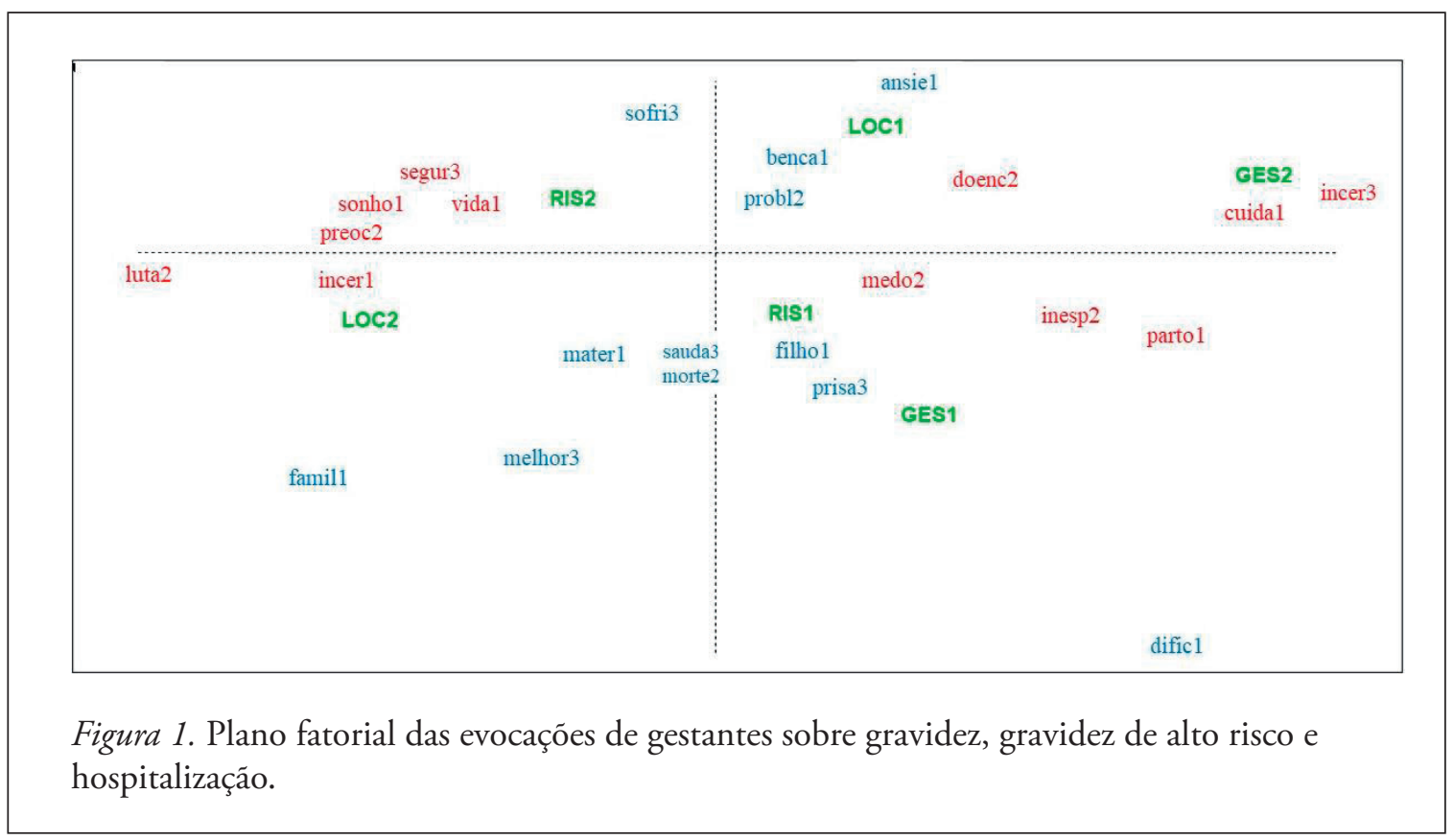

Em relação ao estímulo gravidez, no eixo F1, horizontal, as palavras mais representativas e a sua correspondência por fator $(\mathrm{CPF})$, no lado direito foram: cuidado (CPF: 111) e parto (CPF: 51) relacionado com o grupo de multigestas (CPF: 431) e primigestas (CPF: 247) com risco decorrente da gestação (CPF: 205) hospitalizadas na Santa Casa de Misericórdia de Sobral. E, no lado esquerdo: vida (CPF: 75), sonho (CPF: 54) e incerteza (CPF: 42), relacionado com o grupo de gestantes com risco pré-existente agravado pela gravidez (CPF: 173) hospitalizadas no Hospital Geral Dr. César Cals.

No estímulo 2, gravidez de risco, as palavras mais evocadas no eixo F1, horizontal, lado direito, foram: inesperado (CPF: 45), medo (CPF: 34) e doença (CPF: 33), associado ao risco gestacional decorrente da gravidez, tanto em primigestas como em multigestas. E, no lado esquerdo: preocupação (CPF: 87) e luta (CPF: 53), relacionado com o grupo de gestantes com risco gestacional pré-existente. Quanto ao terceiro estímulo, internamento, no eixo F1, horizontal, no lado direito, as evocaçóes foram: incerteza (CPF: 144), relacionado com o grupo de gestantes com risco decorrente da gravidez. No lado esquerdo: segurança (CPF: 70), relacionado com o grupo de mulheres com risco pré-existente agravado pela gravidez.

No eixo F2, vertical, no que se refere ao estímulo gravidez, as palavras mais representativas no pólo superior foram: benção (CPF: 39) e ansiedade (CPF: 81) por gestantes com risco gestacional pré-existente. E, no pólo inferior: dificuldade (CPF: 184), família (CPF: 69), maternidade (CPF: 48) e filho (CPF: 34), representando o grupo de primigestas com risco decorrente da gestação.

Em relação ao estímulo gravidez de risco, no eixo F2, vertical, tem-se no pólo superior as palavras: problema (CPF: 26), representando o grupo de multigestas com 
risco pré-existente agravado. E, no pólo inferior, a palavra morte (CPF: 50), representando o grupo de primigestas com risco decorrente da gestação.

Ainda no eixo F2, as evocaçóes emitidas para o terceiro estímulo no pólo superior, foram: sofrimento (CPF: 72), representando o grupo de multigestas com risco agravado e hospitalizadas na Santa Casa de Misericórdia de Sobral. E, no pólo inferior: prisão (CPF: 69), melhorar (CPF: 50), saudade (CPF: 28), representando as primigestas com risco decorrente da gestação e hospitalizadas no Hospital Geral Dr. César Cals.

Os elementos que organizam as representações sociais são apresentados e discutidos conforme as variáveis fixas e as características das gestantes com a finalidade de apreender os sentidos atribuídos. A Figura 2, por sua vez, apresenta o universo consensual das representaçóes sociais sobre a experiência de gestantes com a gravidez de alto risco no contexto da hospitalização.

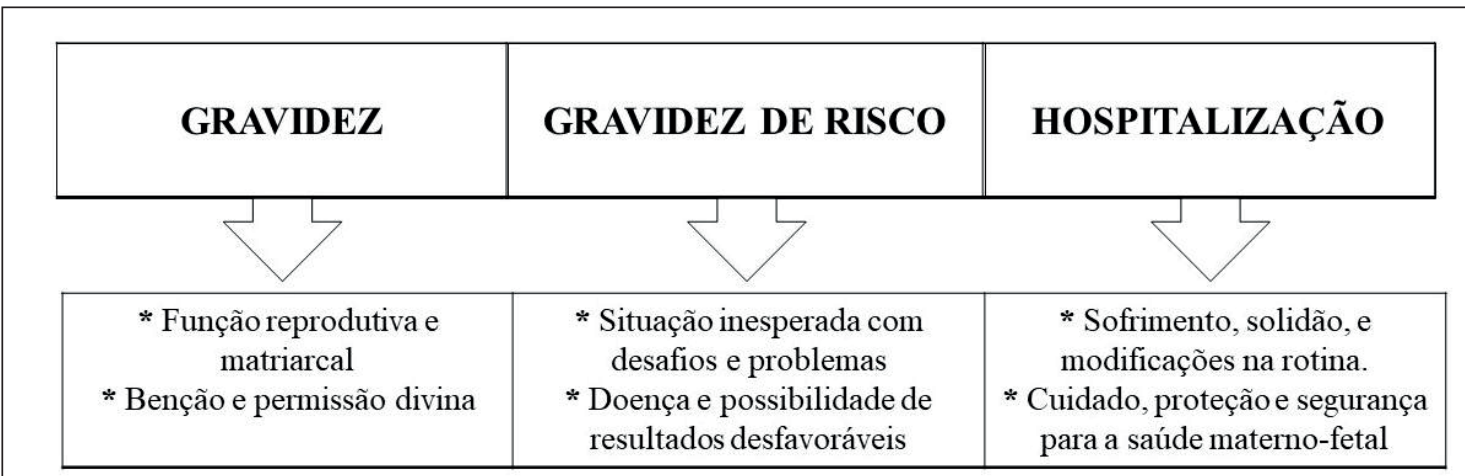

Figura 2. Representaçôes sociais de gestantes sobre gravidez, gravidez de alto risco e hospitalização no ciclo gravídico.

\section{Discussão}

As características sociodemográficas e obstétricas das gestantes deste estudo convergem com o perfil de gestantes de alto risco evidenciados em outros estudos realizados em maternidades em diferentes regiōes do país ao longo dos anos (Jantsch et al., 2017; Moura et al., 2018).

Observa-se a partir das evocações que existe diferença significativa no campo representacional sobre gravidez e gravidez de risco. A primeira, considerada benção, sonho, capacidade de gerar um filho e com forte associaçáo à maternidade, constituiçáo familiar e cuidado, evidenciando sentidos que transpassam os aspetos físicos e orgânicos. A gravidez de risco, no entanto, é percecionada num contexto desafiador, de complicaçóes inesperadas, traduzidas em doença e problema, despertando sensações de medo e preocupação.

Estas construçóes fazem parte do universo consensual e do estereótipo feminino que permeiam os discursos e as crenças sociais ao longo dos anos, percebendo a conotação divina e a forte crença religiosa que permeiam as representaçóes acerca da gravidez e a associação da figura feminina à esfera familiar de reprodução e maternidade, constatando-se a influência da gravidez para a constituição da identidade social da mulher (Coelho et al., 2017; Resende, 2017) e, reforçando o carácter de representação social ao nortear as interpretaçóes e os sentidos que as pessoas têm sobre objetos sociais relevantes.

Contudo, essas representaçôes não são únicas e cristalizadas, pois a gravidez passou a representar incerteza e dificuldade, que estavam relacionadas com a condição particular das grávidas deste estudo, o diagnóstico de gravidez de alto risco. Neste contexto, ainda que a gra- videz seja um sonho, uma construção poetizada, pode despertar na mulher sensações ambivalentes, intercalando contentamento e desafio. Infere-se que essas sensaçóes coexistem como resultado de uma indeterminaçáo do desfecho da gravidez e de uma ameaça à vida e/ou à saúde dessas gestantes e dos seus filhos, presente em todo o período gestacional até ao parto e nascimento (Oliveira \& Mandú, 2015; Wilhelm et al., 2015; Cabral et al., 2018; Costa et al., 2019).

Para as gestantes cujo diagnóstico de alto risco foi atribuído ao desenvolvimento do ciclo gravídico, a objetivação da gravidez processou-se no parto, no cuidado, em instituiçôes sociais como a família e na figura da maternidade e do filho, que passam a ter significado após a gravidez. A palavra dificuldade revela um contexto percebido por estas gestantes devido ao risco que estavam a vivenciar. Já para as gestantes com risco pré-existente agravado pela gravidez, as evocações benção, sonho e vida revelam o enaltecimento da gravidez, já a ansiedade e a incerteza agregam a representação de que a gravidez é uma condição de descobertas e adaptaçóes na qual a evolução do ciclo gestacional concorre com o desenvolvimento de algum fator agravante existente anteriormente e portanto, para esse grupo de mulheres, a gestação passa a representar a superação da sua condição de risco.

A gestação é um processo considerado fisiológico e tende-se a acreditar a priori que tudo transcorrerá de forma natural. De outro modo, a gestaçáo de alto risco foge ao dito normal, esperado ou desejado, portanto é algo não familiar que necessita de ser inserido e interpretado na vida e no saber das gestantes, o que caracteriza uma das funções das representaçôes socais. Nesta lógica, as gestantes elaboraram a gravidez de alto risco e tornaram-na 
compreensível no seu mundo, significando uma experiência envolvida em perigos, complicaçóes, dificuldades e problemas, cuja morte e perda eram possibilidades reais e temidas.

Esta representação foi produzida a partir dos saberes compartilhados no quotidiano dos grupos sociais, o conhecimento do senso comum, a partir das interaçôes com outras gestantes, das informaçóes divulgadas, dos diálogos com os profissionais de saúde, de gestaçóes anteriores e do convívio social, a gestaçáo de alto risco passou a ser ancorada em possíveis resultados desfavoráveis e objetivada em sentimentos e sensaçóes desagradáveis.

Para o grupo de mulheres cujo risco surgiu após a gestação (RIS1), a gravidez de alto risco foi inesperada, contrária às suas expectativas, pois após a gravidez estas passaram a desenvolver alterações que foram ancoradas na doença, no medo e na morte, que no seu universo consensual seriam consequências da gravidez de alto risco. Mesmo na gestação que evolui normalmente do ponto de vista obstétrico, surgem receios e intuiçôes referentes à morte, mas é na gravidez de risco que se aguçam os medos e a morte se transforma numa ameaça potencial (Cabral et al., 2018; Wilhelm et al., 2015).

Já as gestantes que possuíam fator de risco agravado pela gravidez (RIS2) representaram-na como preocupação, luta e problema, uma vez que esse fator pré-existente consiste num desafio para o desenvolvimento do ciclo gravídico. A palavra luta, expressa para as gestantes o duelo entre a gestação versus o fator de risco e essa perceção sobre a sua gravidez tem a objetivação na preocupação. Para essas gestantes, engravidar é a própria superação diante da condição de risco, onde é preponderante o desejo de tornar-se mãe e atender às expectativas quanto ao seu papel reprodutivo, reforçando a imagem da mulher-máe e retificando esse conteúdo da representação social sobre a gravidez.

Quanto ao local de internamento, observa-se que em ambos os cenários as evocaçóes apontam os aspetos positivos e negativos relacionados com a experiência, o que permite inferir que mesmo sendo locais diferentes, as realidades evidenciam-se semelhantes e as representaçóes que giram em torno do processo de hospitalização estão associadas ao próprio fenómeno e às vivências e interações das gestantes.

As gestantes de alto risco deste estudo, assim como as do estudo de Ferreira et al. (2019), apreendem o internamento como uma fase de angústia, solidão, sofrimento e saudade, uma vez que constitui uma nova condição, não prevista, que as distancia do seu quotidiano e que requer adaptaçóes emocionais e estruturais, sendo o hospital um local de dor e sofrimento, pois afastava-as da sua vida, da sua casa, do seu trabalho, da sua família e aproximava-as da confirmação da sua condição de risco.

Por outro lado, o internamento significou para estas mulheres segurança e possibilidade de melhorar, reconhecendo-o também como um local de proteção, cuidados e suporte para manutenção da gravidez. Estudos de Piveta et al. (2016) e Costa et al. (2019) corroboram esta ideia, afirmando que o reconhecimento da necessidade de monitorização da gravidez contribui para a aceitação e para a segurança destas mulheres devido à assistência recebida e à vigilância contínua do bem-estar fetal que de outra forma não poderiam receber.

Tais perceçóes sobre a hospitalização coadunam com as representaçóes sobre a gravidez de alto risco, uma vez que a gravidez no contexto do alto risco foi considerada uma doença, uma situação inesperada e problemática, associada à morte, na qual seria o hospital o espaço adequado para tratamento, cuidado e consequente melhora das condições de risco. Este pensamento sustenta a sensação de segurança e conforta as gestantes quanto à necessidade da hospitalizaçáo para o acompanhamento e monitorização da gravidez. As representaçóes sociais acerca da hospitalização durante o período gestacional também são produto dos processos de interaçấo e comunicação vivenciados ao longo das suas vidas e durante essa fase, através do contacto com gestantes em condição semelhante e com a equipa de profissionais, sofrendo, assim, o que pode resultar da influência do sistema de valores e ideias presentes na sociedade, que orienta pensamentos, comportamentos e açôes.

Evidenciam-se como limitações o número de participantes e a restrição a duas maternidades públicas de referência do estado do Ceará, devendo ser ampliado para as demais, incluindo os serviços da rede privada que também atendem gestantes de alto risco, além de investigar o fenómeno sob a ótica de profissionais e familiares que também experienciam a gravidez de alto risco no contexto hospitalar. No entanto, os resultados suscitam reflexóes sobre as açóes dos profissionais, apresentando contribuições para uma prática clínica que vá ao encontro dos saberes e das experiências das gestantes de alto risco, minimizando as fragilidades e os impactos da hospitalização.

\section{Conclusão}

Apresentaram-se os elementos consensuais, coletivamente compartilhados, normativos e concretizados em torno dos quais as representaçóes sociais das gestantes sobre gravidez, gravidez de alto risco e hospitalização foram ancoradas e objetivadas. As evocaçóes sinalizam as representaçōes sociais acerca da gravidez, construídas com uma valorização do núcleo familiar, objetivando-a numa permissão divina e na imagem do filho e ancorando-a na função reprodutiva e matriarcal, uma vez que é na família que nasce o encontro com a maternidade e com as crenças e valores que serão bases para o desenvolvimento do papel materno por essas mulheres.

Revelam uma multiplicidade de sentimentos e sensaçóes ao tomar consciência de uma gravidez de alto risco. A mulher vive a rutura da gestaçáo idealizada e passa a lamentar e lutar contra o resultado incerto da gravidez, contudo não anula a satisfação de estar grávida, reforçando o papel biológico da mulher representado pela maternidade mesmo sob condiçóes de risco.

A hospitalização constituiu-se como numa experiência ímpar na vida da gestante, um evento particular à condição de alto risco, fortaleceu os sentimentos negativos, acentuou o stress, mas também denotou terapêutica, atendimento especializado, cuidado e proteçáo para o 
binómio mãe-filho, simbolizando a possibilidade de um desfecho favorável para a gestação e nascimento. Verifica-se a necessidade de desenvolver intervençôes e estratégias capazes de monitorizar as complicaçóes e reduzir os internamentos hospitalares de gestantes de alto risco, de modo a garantir a segurança materno-fetal e preservar a vida, a rotina, os laços e a experiência familiar positiva da gravidez. Torna-se fundamental oferecer uma assistência respeitadora, individualizada, direcionada para as necessidades da gestante e que englobe os seus modos de compreender o fenómeno e minimize os sofrimentos e angústias sentidos durante esta fase.

\section{Contribuiçáo de autores}

Conceptualização: Rodrigues, A. R. M., Rodrigues, D. P. Investigação: Rodrigues, A. R. M.

Análise formal: Rodrigues, A. R. M.

Redação - rascunho original: Rodrigues, A. R. M., Silveira, M. A., Paiva, A. M., Fialho, A. V., Queiroz, A. B., Rodrigues, D. P.

Revisão - análise e edição: Rodrigues, A. R. M., Silveira, M. A., Paiva, A. M., Fialho, A. V., Queiroz, A. B., Rodrigues, D. P.

\section{Referências bibliográficas}

Cabral, S. A., Alencar, M. C., Carmo, L. A., Barbosa, S. E., Barros, A. C., \& Barros, J. K. (2018). Receios na gestação de alto risco: Uma análise da percepção das gestantes no pré-natal. Revista Multidisciplinar e de Psicologia, 12(40), 151-162. Recuperado de https://idonline.emnuvens.com.br/id/article/view/1051/1515

Coelho, D. D., Souza, J. L., Torres, M. M., \& Drezett, J. (2017). Gravidez e maternidade tardia: Sentimentos e vivências de mulheres em uma unidade de pré - natal de alto risco em Barreiras, Bahia. Revista das Ciências da Saúde do Oeste Baiano, 2(1), 1-19. Recuperado de http://fasb.edu.br/revista/index.php/higia/article/ view/145

Costa, L. D., Hoesel, T. C., Teixeira G. T., Trevisan, M. G., Backes, M. T., \& Santos, E. K. (2019). Percepçóes de gestantes internadas em um serviço de referência em alto risco. Revista Mineira de Enfermagem, 23, 1199. doi:10.5935/1415-2762.20190047

Coutinho, M. P. (2017). A técnica de associação livre de palavras sobre o prisma do software TRI-DEUX-MOTS (version 5.2). Revista Campo do Saber, 1(3), 219-43. Recuperado de http://periodicos. iesp.edu.br/index.php/campodosaber/article/viewFile/72/58.

Ferreira, S. V., Soares, M. C., Cecagno, S., Alves, C. N., Soares, T. M., \& Braga, L. R. (2019). Cuidado de enfermagem na ótica das gestantes de alto risco. Revista Família, Ciclos de Vida e Saúde no Contexto Social, 7(2),143-150. Recuperado de http://seer.uftm.edu.br/revistaeletronica/index.pdfhp/refacs/article/view/3410/pdf

Gregorio, S. B., \& Mariot, M. D.(2019). Care in high risk gestation in the perception of nurses, pregnant women and family: An integrative review. Revista Cuidado em Enfermagem, 5(6), 1-18. Jantsch, P. F., Carreno, I., Pozzobon, A., Adami, F. S., Leal, C. S., Mathias, T.C., ... Bergo, P. H. (2017). Principais características das gestantes de alto risco da região central do Rio Grande do Sul. Destaques Acadêmicos, 9(3), 272-282. Recuperado de http:// univates.br/revistas/index.php/destaques/article/view/1534.

Lawn, J. E., Blencowe, H., Waiswa, P., Amouzou, A., Mathers, C., Hogan, D., Flenady, V., Froen, J. F., ... Cousens, S. (2016). Stillbirths: Rates, risk factors, and acceleration towards 2030. Lancet, 387, 587-603. doi:10.1016/S0140-6736(15)00837-5

Martins, A. C., \& Silva, L. S. (2018). Epidemiological profile of maternal mortality. Revista Brasileira de Enfermagem, 71(Supll. 1), 677-83. doi:10.1590/0034-7167-2017-0624

Moura, B. L., Alencar, G. P., Silva, Z. P., \& Almeida, M. F. (2018). Internações por complicações obstétricas na gestação e desfechos maternos e perinatais, em uma coorte de gestantes no Sistema Único de Saúde no Município de São Paulo, Brasil. Caderno de Saúde Pública, 34(1), e00188016. doi: 10.1590/0102-311X00188016.

Ministério da Saúde. (2012). Gestação de alto risco: Manual técnico. Brasília, Brasil: Autor. Recuperado de http://bvsms.saude.gov.br/ bvs/publicacoes/manual_tecnico_gestacao_alto_risco.pdf

Moscovici, S. (2013). Representaçôes sociais: Investigaçôes em psicologia social (10 a ed). Petrópolis, Brasil: Vozes.

Oliveira, D. C., \& Mandú, E. N. (2015). Women with high-risk pregnancy: Experiences and perceptions of needs and care. Escola Anna Nery Revista de Enfermagem, 19(1), 93-101. doi:10.5935/14148145.20150013

Piveta, V., Bernardy, C. C., \& Sodré, T. M. (2016). Perception of pregnancy risk by a group of pregnant women hypertensive hospitalized. Ciência cuidado e saúde, 15(1), 61-68. Recuperado de http://periodicos.uem.br/ojs/index.php/CiencCuidSaude/article/ view/28988.

Portaria no 1.020, de 29 de maio de 2013. Diário Oficial da União $n^{o}$ 103 - Secção 1. Ministério da Saúde. Brasília, Brazil. Retrieved from https://bvsms.saude.gov.br/bvs/saudelegis/gm/2013/ prt1020_29_05_2013.html

Resende, D. K. (2017). Maternidade: Uma construção histórica e social. Pretextos - Revista da Graduação em Psicologia da PUC Minas, 2(4), 175- 191. Recuperado de http://periodicos.pucminas.br/ index.php/pretextos/article/view/15251

Sehnem, G. D., Saldanha, L. S., Arboit, J., Ribeiro, A. C., \& Paula, F. M. (2020). Prenatal consultation in primary health care: Weaknesses and strengths of Brazilian nurses' performance. Revista de Enfermagem Referência, 5(1), e19050. doi: 10.12707/RIV19050

Sousa, D. M., Sales, F. A., Oliveira, J. H., \& Chagas, A. C. (2018). Caracterização das gestantes de alto risco atendidas em um centro de atendimento à mulher e o papel do enfermeiro nesse período. Revista de Atenção à Saúde, 16(56), 54-62. doi:10.13037/ras. vol16n56.5120

Wilhelm, L. A., Alves, C. N., Demori, C. C., Silva, S. C., Meincke, S. M., \& Ressel, L. B. (2015). Feelings of women who experienced a high-risk pregnancy: A descriptive study. Brazilian Journal of Nursing, 14(3), 284-93. Recuperado de http://www.objnursing. uff.br/index.php/nursing/article/view/5206 